\title{
The effects of early-stage neurodevelopmental treatment on the growth of premature infants in neonatal intensive care unit
}

\author{
Eun-Ju Lee, Sang-Yeol Lee* \\ Department of Physical Therapy, College of Science, Kyungsung University, Busan, Korea
}

The purpose of this study was to investigate the effects of early-stage neurodevelopmental treatment on the growth of premature infants in the neonatal intensive care unit. A total of 85 premature infants were included in this study. Infants with a birth weight of less than $2.5 \mathrm{~kg}$ and of $2.5 \mathrm{~kg}$ or higher were classified as premature infants with a high risk of growth delay and with a low risk of growth delay respectively. Of the 55 premature infants with a high risk of growth delay, 27 premature infants were placed in the intervention group and 28 were placed in the control group according to their hospitalization time. Thirty premature infants with a low risk of growth delay were included in the comparative group. The same general nursing care of the neonatal intensive care unit was provided to the intervention group, the control group, and the comparative group, but an additional neurodevelopmental treatment program was given only to the intervention group, for 15 min per session, 4 times a week, up to 40 weeks after conception. As growth indicators, the body weight and head circumference were measured before and 2 weeks after the intervention, and at 40 weeks after conception when the intervention was completed. The body weight and head circumference of the intervention group, which received the neurodevelopmental treatment, were significantly improved compared to the control group $(P<0.05)$, but they were not significantly different from those of the comparative group. However, the body weight and head circumference of the control.

Keywords: Neurodevelopmental treatment, Growth, Premature infant, Neonatal intensive care unit

\section{INTRODUCTION}

Recently, the total fertility rate of Korea has remained extremely low at 1.17 , posing the risk of population decline in the long run. While this extremely low birth rate continues, the incidence of premature infants with a gestational age of less than 37 weeks was $7.2 \%$ in 2016, a 1.5-fold increase from 2006, and the incidence of infants with a birth weight of less than $2.5 \mathrm{~kg}$ was $5.9 \%$, an approximately 2-fold increase from 1996 (Korean Statistics Information Service, 2018). Premature infants, unlike normal fullterm infants, are prone to general health problems, such as chronic respiratory disease, anemia, hearing loss, lactation problems, and retinopathy of prematurity, depending on the degree of postnatal maturity and disease. These health problems force them to be ad- mitted to neonatal intensive care units for medical interventions and care, such as oxygen treatment, artificial ventilation, maintenance of vital signs, insulation, prevention of infection, and supply of nutrition, for several weeks up to several months (White-Traut, 2004).

The environment of the neonatal intensive care unit for premature infants is characterized by body fixation due to the connections with various medical devices, difficulty of antigravity movement given immature physical development condition, bright lighting, excessive noise, and contact with the hard floor and plastic walls of the incubator. This is quite different from the uterine environment, which provides appropriate sensory stimuli, such as tactile, vestibular, visual, and auditory sensations in contact with the amniotic fluid (Blackburn, 1998). These conditions induce

\footnotetext{
${ }^{*}$ Corresponding author: Sang-Yeol Lee (iD https://orcid.org/0000-0003-4428-9101 Department of Physical Therapy, College of Science, Kyungsung University, 309 Suyeong-ro, Nam-gu, Busan 48434, Korea

Tel: +82-51-663-4873, Fax: +82-51-628-4870, E-mail: sjslh486@hanmail.net Received: April 13, 2018 / Accepted: May 8, 2018
}

This is an Open Access article distributed under the terms of the Creative Commons Attribution Non-Commercial License (http://creativecommons.org/licenses/by-nc/4.0/) which permits unrestricted non-commercial use, distribution, and reproduction in any medium, provided the original work is properly cited. 
stress responses in premature infants, which may interfere with normal growth due to elevated intracranial pressure, apnea, peripheral vasoconstriction, decreased gastrointestinal motility, and secretion of stress hormones, such as cortisol and catecholamines (Cabral et al., 2014).

Growth refers to the process of quantitative increase of the body and generally means an increase in body weight, height, and head circumference (Sung, 2009). Trends in the changes in growth measurements of children are very good indicators of their health status. Children with good growth generally show good neurodevelopmental outcomes, while those with poor growth show increased risk of delayed neural development (Belfort et al., 2011; Claas et al., 2011; Euser et al., 2008; Steward, 2012).

Holditch-Davis et al. (2000) and Lester et al. (2002) argued that the abnormal sensory stimuli experienced by premature infants are likely to induce physiological instability, delaying behavioral and physiological responses and inhibiting normal growth, so interventions of normal sensory stimuli should be provided to them. However, premature infants receiving medical treatment for survival in a neonatal intensive care unit have difficulties in receiving proper sensory stimulation interventions for promoting normal growth and development due to their unstable physiological condition. In addition, excessive sensory stimulation interventions may cause stress to premature infants, accelerating abnormal posture, tension, and movement (Umphred, 1983). In other words, even interventions that are considered mild and safe in other settings may have serious and irreversible consequences for premature infants in the neonatal intensive care unit. Therefore, when sensory stimulation interventions are applied to premature infants, very careful attention should be paid in order to prevent premature infants, who are in a vulnerable and unstable condition, from experiencing stress by carefully controlling the intensity and amount of intervention, taking the physiological condition of the individual infants into account.

Neurodevelopmental therapy is one of the intervention methods used in physical therapy, and is applied to help patients with injuries of the central nervous system to control normal postures and promote proper development. During the intervention process, neurodevelopmental treatment generates various sensory inputs, such as tactile, proprioceptive, vestibular, visual, and auditory sensations. In addition, neurodevelopmental treatment is not a strictly defined and uniformized intervention method, but the intensity and amount of neurodevelopmental treatment can be adjusted by selecting and fusing several sensory stimuli according to the individual's health condition. Therefore, it can be safely ap- plied to premature infants who are in various physiological states (Tekin et al., 2018).

The physical therapist is an expert on normal posture control and neurodevelopment who can provide various sensory stimuli to optimize the brain and shape movement in order to improve the patient's health. In the neonatal intensive care unit, physical therapists can help premature infants grow by enhancing their posture control, which is necessary for digestion, feeding, and breathing, and by maintaining the range of motion, shaping the skull, and improving movement control, dietary performance, adaptation to the environment, and behavioral stability (McManus and Capistran, 2008). In other countries, where they are recognized for their abilities and expertise in these areas, physical therapists are involved in prenatal interventions in the neonatal intensive care unit as specialists to prevent developmental delays and promote normal development (Cameron et al., 2005; Coutinho et al., 2014; Ferrari et al., 2007; Massaro et al., 2009; Vaivre-Douret et al., 2009). However, in Korea, physical therapists still have only limited access to neonatal intensive care units, and their role as specialists in this area has not been established due to the lack of awareness of early-stage physical therapy to promote growth and development in premature infants.

In this study, we investigated the effects on the growth of premature infants of an early-stage neurodevelopmental treatment performed by a physical therapist in the neonatal intensive care unit, to provide grounds for the use of physical therapists as specialists in neonatal intensive care units.

\section{MATERIALS AND METHODS}

\section{Subjects}

Premature infants admitted to the neonatal intensive care unit of Busan St. Mary's Hospital who did not have congenital anomalies or chromosomal abnormalities and whose intraventricular hemorrhage level was grade 2 or below were included in this study. At the beginning of the study, infants with a birth weight of less than $2.5 \mathrm{~kg}$ and of $2.5 \mathrm{~kg}$ or higher were classified as premature infants with a high risk of growth delay and with a low risk of growth delay respectively. Of the 55 premature infants with a high risk of growth delay, 27 were placed in the intervention group and 28 were placed in the control group according to their hospitalization time. Thirty premature infants with a low risk of growth delay were included in the comparative group. The guardians of the premature infants voluntarily participated after hearing sufficient explanation of the study. 


\section{Design}

All subjects participated in the experiment after their vital signs were determined to be stable by the pediatrician. The intervention group, control group, and comparative group were provided with the same nutrition strategy and nursing care, and maintenance of an environment similar to the uterine environment of the mother, which are generally provided in the neonatal intensive care unit. The intervention group additionally received a neurodevelopmental treatment program provided by a physical therapist for $15 \mathrm{~min}$ a session, four times per week up to 40 weeks after conception (postconceptional age). In the present study, all interventions were carefully applied to premature infants by a physical therapist who had completed a course at least equivalent to the Bobath Pediatric Basic Course and who had more than seven years of basic physical therapy experience. Before the application of the therapy, the intensity and amount of therapy were carefully adjusted in consideration of the health condition of individual infants. If an infant showed a stress response due to their unstable physiological condition, the therapy was immediately stopped for safety and the infant was referred to the pediatrician and nurse. This study was approved by the Ethics Committee of Clinical Research in Busan St. Mary's Hospital (approval number: 2012-76).

\section{Neurodevelopmental treatment program}

The neurodevelopmental treatment program used in this study was designed based on previous studies and literature to reduce abnormal postures and movement patterns in premature infants and to allow them to experience more normal posture and sensory stimulation (Cameron et al., 2005; Girolami and Campbell, 1994). In order to promote comfort and support the respiration and musculoskeletal systems of premature infants, they were allowed to experience prenatal physiological flexion postures, such as proper alignment of the head and neck following relaxation of the cervical extensors, slight chin tuck, anterior pulling of the scapula, centering of the arms and hands, backward slope of the pelvis, and flexion of the trunk and legs. This experience with prenatal physiological flexion postures is expected to improve the psychological stability of premature infants and to become a basis for maintaining muscle length, promoting normal alignment of joints, and self-regulating function for antigravity postural development. In order to prevent damage to the skin, promote the development of the skeletal system, and maintain a symmetrical head shape, the posture was changed periodically from a lying posture on the back, to a lying posture on the belly, and to a lying posture on the side in a slow and smooth motion. In addition, the use of the hands and feet of premature infants to touch their own body and tactile and proprioceptive stimuli, such as the therapist gently embracing the premature infants, were used to induce the development of a body image.

\section{Measurements}

Measurements of body weight and head circumference, the indicators of growth in this study, were performed 3 times in total. The initial measurement was performed before the intervention, the interim measurement was performed 2 weeks after the start of the intervention, and the postintervention measurement was performed at 40 weeks after conception. Measurements were completed by a nurse of the neonatal intensive care unit. The body weight was measured using an electronic indicator scale (CAS Computing Scale, CAS USA, East Rutherford, NJ, USA) $1 \mathrm{hr}$ prior to feeding at 10 a.m. after removal of both clothing and diapers. Before the scale was used, it was set to zero. After placing an infant on the scale, the weighing value obtained at the time when there was no more change after the values changed twice was selected and recorded. The head circumference was measured using the same tape measure (Daeyoung Instrument, Seoul, Korea) at 10:00 a.m. The mean value obtained from two measurements over the largest perimeter around the laryngeal bulge from the upper part of the eyebrows and ears of the infant was calculated and recorded.

\section{Statistical analysis}

The results of this study were analyzed using IBM SPSS Statistics ver. 22.0 (IBM Co., Armonk, NY, USA), and the significance level $\alpha$ for all statistics was set to 0.05 . For general characteristics and birth history of the subjects, the birth frequency and mean value were presented. One-way analysis of variance was used for the comparison of the mean growth values between the groups before and after the intervention, and the Scheffe method was used for the posttest analysis.

\section{RESULTS}

\section{General characteristics of subjects}

Table 1 shows the general characteristics of the 85 subjects who participated in the study by group, such as gender, delivery type, multiple birth, and maternal age.

\section{Birth history of subjects}

The results of the comparison of the birth history for each 
Table 1. General characteristics of subjects $(n=85)$

\begin{tabular}{lccr}
\hline Characteristic & Intervention $(n=27)$ & Comparative $(n=30)$ & Control $(n=28)$ \\
\hline Sex & & & \\
Male & $14(51.9)$ & $19(63.3)$ & $14(50)$ \\
Female & $13(48.1)$ & $11(36.7)$ & $14(50)$ \\
Delivery type & & & \\
C-sec & $20(74.1)$ & $21(70)$ & $21(75)$ \\
NSVD & $7(25.9)$ & $9(30)$ & $7(25)$ \\
Multiple birth & & & $12(42.9)$ \\
Yes & $11(40.7)$ & $5(16.7)$ & $16(57.1)$ \\
None & $16(59.3)$ & $25(83.3)$ & $30.43 \pm 4.77$ \\
Maternal age & $31.04 \pm 5.28$ & $33.80 \pm 4.06$ &
\end{tabular}

Values are presented as number (\%) or mean \pm standard deviation.

C-sec, Caesarean section; NSVD, normal spontaneous vaginal delivery.

Table 2. Birth history of subjects $(n=85)$

\begin{tabular}{lrrrcl}
\hline Variable & $\begin{array}{c}\text { Intervention }^{\mathrm{a}} \\
(\mathrm{n}=27)\end{array}$ & $\begin{array}{c}\text { Comparative }^{\mathrm{b}}(\mathrm{n}=30) \\
\text { ( }\end{array}$ & \multicolumn{1}{c}{$\begin{array}{c}\text { Control }^{\mathrm{c}} \\
(\mathrm{n}=28)\end{array}$} & $F$ & Scheffe \\
\hline $\mathrm{GA}(\mathrm{wk})$ & $32.90 \pm 2.42$ & $35.90 \pm 2.45$ & $33.43 \pm 2.60$ & $17.08^{*}$ & $\mathrm{~b}>\mathrm{c}, \mathrm{a}$ \\
$\mathrm{BW}(\mathrm{kg})$ & $1.88 \pm 0.45$ & $2.87 \pm 0.32$ & $1.83 \pm 0.47$ & $58.87^{*}$ & $\mathrm{~b}>\mathrm{a}, \mathrm{c}$ \\
$\mathrm{BHC}(\mathrm{cm})$ & $29.89 \pm 1.85$ & $33.18 \pm 1.31$ & $29.94 \pm 2.55$ & $27.10^{*}$ & $\mathrm{~b}>\mathrm{c}, \mathrm{a}$ \\
$\mathrm{A} / \mathrm{S}(1)$ & $5.37 \pm 1.60$ & $6.63 \pm 1.52$ & $5.96 \pm 1.69$ & $4.39^{*}$ & $\mathrm{~b} \geq \mathrm{c} \geq \mathrm{a}$ \\
$\mathrm{A} / \mathrm{S}(5)$ & $7.41 \pm 1.05$ & $8.10 \pm 1.30$ & $7.68 \pm 1.25$ & 2.40 & $\mathrm{~b}, \mathrm{c}, \mathrm{a}$ \\
\hline
\end{tabular}

Values are presented as mean \pm standard deviation.

GA, gestational age; BW, birth weight; BHC, birth head circumference; A/S (1), Apgar score (1 min); A/S (5), Apgar score (5 min).

${ }^{*} P<0.05$.

group are as follows (Table 2). Gestational age, birth weight, and birth head circumference were not significantly different between the intervention group and the control group, but they were different from the comparative group of healthy premature infants $(P<0.05)$. The Apgar score measured 1 min after birth was significantly different between the intervention group and the control group, but there was no significant difference in the Apgar score measured $5 \mathrm{~min}$ after birth among the three groups.

\section{Changes in body weight for each group}

There was no significant difference in preintervention weight between the intervention group and the control group, but both groups had significantly lower preintervention body weight than the comparative group $(P<0.05)$. At the end of the 40th week after conception, after the intervention was completed, the intervention group showed significantly higher weight gain than the control group $(P<0.05)$, and there was no significant difference in the weight between the intervention group and the comparative group. However, the weight of the control group at the last measurement, 40 weeks after conception, was significantly lower than
Table 3. Changes in body weight for each group $(n=85)$

\begin{tabular}{lccccc} 
Test & $\begin{array}{c}\text { Intervention } \\
(\mathrm{n}=27)\end{array}$ & $\begin{array}{c}\text { Comparative } \\
(\mathrm{n}=30)\end{array}$ & $\begin{array}{c}\text { Control }^{\mathrm{c}} \\
(\mathrm{n}=28)\end{array}$ & $F$ & Scheffe \\
\hline Pre & $1.92 \pm 0.30$ & $2.74 \pm 0.32$ & $1.86 \pm 0.37$ & $63.64^{*}$ & $\mathrm{~b}>\mathrm{a}, \mathrm{c}$ \\
Mid & $2.27 \pm 0.32$ & $3.01 \pm 0.37$ & $2.17 \pm 0.33$ & $52.09^{*}$ & $\mathrm{~b}>\mathrm{a}, \mathrm{c}$ \\
Final & $3.50 \pm 0.60$ & $3.65 \pm 0.46$ & $2.85 \pm 0.48$ & $19.34^{*}$ & $\mathrm{~b}, \mathrm{a}>\mathrm{c}$ \\
\hline
\end{tabular}

Values are presented as mean \pm standard deviation.

${ }^{*} P<0.05$.

Table 4. Changes in head circumference for each group $(n=85)$

\begin{tabular}{lccccl} 
Test & $\begin{array}{c}\text { Intervention } \\
(\mathrm{n}=27)\end{array}$ & $\begin{array}{c}\text { Comparative }^{\mathrm{b}}(\mathrm{n}=30) \\
\text { Pre }\end{array}$ & $\begin{array}{c}\text { Control }^{\mathrm{c}} \\
(\mathrm{n}=28)\end{array}$ & $F$ & Scheffe \\
\hline Mid & $30.05 \pm 1.70$ & $33.05 \pm 1.33$ & $30.02 \pm 2.00$ & $31.25^{*}$ & $\mathrm{~b}>\mathrm{c}, \mathrm{a}$ \\
Final & $35.16 \pm 1.58$ & $32.75 \pm 5.89$ & $31.22 \pm 1.71$ & 1.43 & $\mathrm{~b}, \mathrm{a}, \mathrm{c}$ \\
\hline
\end{tabular}

Values are presented as mean \pm standard deviation.

${ }^{*} P<0.05$.

that of the intervention group as well as that of the comparative group $(P<0.05)$ (Table 3).

\section{Changes in head circumference for each group}

The initial head circumference before the intervention was not different between the intervention group and the control group, but the head circumference of both groups was smaller than that of the comparative group $(P<0.05)$. There was no significant difference in head circumference among the three groups after 2 weeks of intervention. However, at 40 weeks after conception, after the intervention was completed, the head circumference of the intervention group was significantly higher than that of the control group $(P<0.05)$, but it was not significantly different from the comparative group. The head circumference of the control group at the last measurement, 40 weeks after conception, was significantly lower than that of the intervention group as well as that of the comparative group $(P<0.05)$ (Table 4).

\section{DISCUSSION}

Premature infants born with an immature physiological status are more likely to experience growth retardation because they are placed in a different environment than the maternal uterus, which may cause problems with growth and development as their gestational age is shorter and birth weight smaller (Claas, 2011). Factors that influence the growth of premature infants include intrauterine growth restriction, bronchial dysplasia, respiratory pattern, hypoxemic symptoms, elevated postpartum adrenocortical 
hormones, decreased liquid aspiration, nutritional problems, and infection (Kuschel and Harding, 2004). Premature infants also have difficulty feeding due to unusual oral sensations related to feeding tubes, frequent medical interventions, secured airway for breathing, and excessively stretched posture of the neck and head due to their immature muscle development state. Adams-Chapman et al. (2013) studied 1,477 premature infants with a gestational age of less than 26 weeks and reported that the difficulty they experienced when feeding caused delayed growth.

In order to reduce the delay in growth, children born as premature infants should be well taken care of to avoid problems. General nursing interventions performed in the neonatal intensive care unit include feeding and nutrition strategies, taking a flexion posture along the body center line, maintaining the same brightness as in the mother's womb using an incubator cover, blocking some noise, and using a pacifier. These interventions provide an environment with less stress to premature infants, facilitating maturation of their vestibular system, tactile sense, auditory sense, and visual sense, and enhanced abilities thereof (White-Traut et al., 2002). In the present study, the physical therapist tried to help premature infants with a high risk of growth delay to grow, by applying a neurodevelopmental treatment program in addition to general nursing care. The results of the study showed that the intervention group of low-weight premature infants treated with the neurodevelopmental treatment not only showed significantly higher body weight and head circumference growth than the control group, who received general nursing care alone, but also caught up with the growth of the comparative group of healthy premature infants. In contrast, the control group, who received the general nursing care alone, not only failed to catch up with the growth of the comparative group of healthy premature infants, but also showed a significantly lower growth rate than the intervention group. These results demonstrated that additional neurodevelopmental treatment performed by a physical therapist was an effective intervention method for improving growth in premature infants.

Growth is a dynamic process, closely related to mental and social health as well as to physical aspects, and is also influenced by normal development in a reciprocal manner (Sung, 2009). Among premature infants, those born with a low body weight in particular are at great risk of insufficient growth during the first year. Premature infants who have not caught up with normal growth during early childhood are at higher risk of having developmental delays and medical problems than premature infants with normal growth during early childhood (Claas et al., 2011). In a study in which tactile motor stimulation was applied to 160 premature infants, Ahmed et al. (2015) reported that tactile motor stimulation was effective in increasing weight and reducing length of hospital stay for premature infants. Ferber et al. (2005) reported that tactile stimulation, such as massage contact, increased the secretion of gastrin and insulin by enhancing the response of the vagus nerve, which increased the food intake rate, thereby promoting the growth of premature infants. These findings suggest that, because the neurodevelopmental treatment program provided in this study involved complex sensory stimuli, including tactile stimulation, it was likely to be effective in weight gain and head circumference growth by affecting hormone secretion in premature infants.

The growth indicators used in this study were weight gain and head circumference. This is because most of the growth indicators in infancy are mainly concerned with weight gain, and most of them judge pathological state by weight evaluation (Steward, 2012). In addition, because the rate of weight gain is 3 times faster than that of height increase before age one, growth problems are more sensitively manifested as weight change than height change. Therefore, growth status is usually assessed by weight, and rapid weight gain in premature infants may indicate shorter hospitalization stays (Symington and Pinelli, 2006). The head circumference requires special attention during the first year after birth. The head circumference at birth is about $34 \mathrm{~cm}$, slightly larger than the chest circumference, and it reaches about $90 \%$ of adult circumference by age four. Although head circumference does not, in reality, reflect growth as well as weight, it is very important in screening diseases such as microcephaly or hydrocephalus. Inadequate growth or excessive growth of head circumference indicates a likelihood of low cognitive development in the future (Brandt et al., 2003; Sammallahti et al., 2014; Weisglas-Kuperus et al., 2009).

In a study in which the growth patterns of 267 premature infants were monitored up to 40 weeks after conception, Ahn et al. (2011) reported that the more severely premature an infant, the smaller their body weight, height, and head circumference, and that the uterine environment is more favorable for fetal growth than any environment provided by a neonatal intensive care unit, no matter how good it is. In the present study, a physical therapist provided early-stage neurodevelopmental treatment to premature infants who were not able to stay in the maternal uterus for various reasons and, thus, were in need of care in a neonatal intensive care unit. As a result, their weight and head circumference at the postconceptional age of 40 weeks caught up with those of the 
comparative group of healthy premature infants. This shows that extra neurodevelopmental treatment performed by physical therapists, in addition to general nursing care in the neonatal intensive care unit, may be an effective intervention method for premature infants that can prevent medical problems related to poor growth in the future.

Nonetheless, even if neurodevelopmental treatment is an intervention method that can be adjusted to the individual infant's health status, dangerous situations that may occur in association with the characteristics of premature infants classified as high-risk newborns may become a limiting factor in the intervention provided by physical therapists in the neonatal intensive care unit. In order to ensure the safe and universal application of neurodevelopmental treatment interventions that can help premature infants grow in the neonatal intensive care unit, clinical training and education in emergencies related to premature infants should precede any implementation of this treatment.

\section{CONFLICT OF INTEREST}

No potential conflict of interest relevant to this article was reported.

\section{ACKNOWLEDGMENTS}

This work was supported by the National Research Foundation of Korea (NRF) grant funded by the Korea government (MSIP; Ministry of Science, ICT \& Future Planning) (No. 2017R1C1B50 15093).

\section{REFERENCES}

Adams-Chapman I, Bann CM, Vaucher YE, Stoll BJ; Eunice Kennedy Shriver National Institute of Child Health and Human Development Neonatal Research Network. Association between feeding difficulties and language delay in preterm infants using Bayley Scales of Infant Development-Third Edition. J Pediatr 2013;163:680-685.e1-3.

Ahmed RG, Suliman GI, Elfakey WA, Salih KM, El-Amin EI, Ahmed WA,

Khalid KE. Effect of tactile kinesthetic stimulation on preterm infants' weight and length of hospital stay in Khartoum, Sudan. Saudi Med J 2015;36:196-199.

Ahn Y, Sohn M, Lee S. Growth patterns of premature infants up to 40th term week of corrected age. J Korean Acad Nurs 2011;41:613-622.

Belfort MB, Rifas-Shiman SL, Sullivan T, Collins CT, McPhee AJ, Ryan P, Kleinman KP, Gillman MW, Gibson RA, Makrides M. Infant growth before and after term: effects on neurodevelopment in preterm infants. Pediatrics 2011;128:e899-906.

Blackburn S. Environmental impact of the NICU on developmental outcomes. J Pediatr Nurs 1998;13:279-289.

Brandt I, Sticker EJ, Lentze MJ. Catch-up growth of head circumference of very low birth weight, small for gestational age preterm infants and mental development to adulthood. J Pediatr 2003;142:463-468.

Cabral TI, Pereira da Silva LG, Tudella E, Simões Martinez CM. Motor development and sensory processing: a comparative study between preterm and term infants. Res Dev Disabil 2014;36C:102-107.

Cameron EC, Maehle V, Reid J. The effects of an early physical therapy intervention for very preterm, very low birth weight infants: a randomized controlled clinical trial. Pediatr Phys Ther 2005;17:107-119.

Claas MJ, de Vries LS, Koopman C, Uniken Venema MM, Eijsermans MJ, Bruinse HW, Verrijn Stuart AA. Postnatal growth of preterm born children $\leq 750 \mathrm{~g}$ at birth. Early Hum Dev 2011;87:495-507.

Coutinho GA, Lemos DM, Caldeira AP. Impact of physiotherapy on neuromotor development of premature newborns. Fisiothe Mov 2014;27: 413-420.

Euser AM, de Wit CC, Finken MJ, Rijken M, Wit JM. Growth of preterm born children. Horm Res 2008;70:319-328.

Ferber SG, Feldman R, Kohelet D, Kuint J, Dollberg S, Arbel E, Weller A. Massage therapy facilitates mother-infant interaction in premature infants. Infant Behav Dev 2005;28:74-81.

Ferrari F, Bertoncelli N, Gallo C, Roversi MF, Guerra MP, Ranzi A, Hadders-Algra M. Posture and movement in healthy preterm infants in supine position in and outside the nest. Arch Dis Child Fetal Neonatal Ed 2007;92:F386-390.

Girolami GL, Campbell SK. Efficacy of a neuro-developmental treatment program to improve motor control in infants born prematurely. Pediatr Phys Ther 1994;6:175-184.

Holditch-Davis D, Bartlett TR, Belyea M. Developmental problems and interactions between mothers and prematurely born children. J Pediatr Nurs 2000;15:157-167.

Korean Statistics Information Service. 2016 Annual report on live births and deaths statistics [Internet]. Daejeon (Korea); 2018 [cited 2018 Feb 6]. Available from: http://kosis.kr/publication/publicationThema.do.

Kuschel CA, Harding JE. Multicomponent fortified human milk for promoting growth in preterm infants. Cochrane Database Syst Rev 2004; (1):CD000343.

Lester BM, Tronick EZ, LaGasse L, Seifer R, Bauer CR, Shankaran S, Bada HS, Wright LL, Smeriglio VL, Lu J, Finnegan LP, Maza PL. The maternal lifestyle study: effects of substance exposure during pregnancy on neurodevelopmental outcome in 1-month-old infants. Pediatrics 2002; 110:1182-1192. 
Massaro AN, Hammad TA, Jazzo B, Aly H. Massage with kinesthetic stimulation improves weight gain in preterm infants. J Perinatol 2009; 29:352-357.

McManus BM, Capistran PS. A case presentation of early intervention with dolichocephaly in the NICU: collaboration between the primary nursing team and the developmental care specialist. Neonatal Netw 2008;27:307-315.

Sammallahti S, Pyhälä R, Lahti M, Lahti J, Pesonen AK, Heinonen K, Hovi P, Eriksson JG, Strang-Karlsson S, Andersson S, Järvenpää AL, Kajantie E, Räikkönen K. Infant growth after preterm birth and neurocognitive abilities in young adulthood. J Pediatr 2014;165:1109-1115.e3.

Steward DK. Growth outcomes of preterm infants in the neonatal intensive care unit: long-term considerations. Newborn Infant Nurs Rev 2012;12:214-220

Sung IK. Monitoring growth in childhood: practical clinical guide. J Korean Med Assoc 2009;52:211-224.

Symington A, Pinelli J. Developmental care for promoting development and preventing morbidity in preterm infants. Cochrane Database Syst Rev 2006;(2):CD001814.

Tekin F, Kavlak E, Cavlak U, Altug F. Effectiveness of Neuro-Developmental Treatment (Bobath Concept) on postural control and balance in Cerebral Palsied children. J Back Musculoskelet Rehabil 2018;31: 397-403.

Umphred D. Conceptual model of an approach to the sensorimotor treatment of the head-injured client. Phys Ther 1983;63:1983-1987.

Vaivre-Douret L, Oriot D, Blossier P, Py A, Kasolter-Péré M, Zwang J. The effect of multimodal stimulation and cutaneous application of vegetable oils on neonatal development in preterm infants: a randomized controlled trial. Child Care Health Dev 2009;35:96-105.

Weisglas-Kuperus N, Hille ET, Duivenvoorden HJ, Finken MJ, Wit JM, van Buuren S, van Goudoever JB, Verloove-Vanhorick SP; Dutch POPS19 Collaborative Study Group. Intelligence of very preterm or very low birthweight infants in young adulthood. Arch Dis Child Fetal Neonatal Ed 2009;94:F196-200.

White-Traut RC, Nelson MN, Silvestri JM, Patel M, Berbaum M, Gu GG, Rey PM. Developmental patterns of physiological response to a multisensory intervention in extremely premature and high-risk infants. J Obstet Gynecol Neonatal Nurs 2004;33:266-275.

White-Traut RC, Nelson MN, Silvestri JM, Vasan U, Littau S, MeleedyRey P, Gu G, Patel M. Effect of auditory, tactile, visual, and vestibular intervention on length of stay, alertness, and feeding progression in preterm infants. Dev Med Child Neurol 2002;44:91-97. 